\title{
Synthesis of Nanoparticles of Fe-Co-Ni Three-component Alloy Capsulated Into Carbon Matrix of Fe-Co-Ni/C Nanocomposites
}

\author{
D.G. Muratovi,2,*, L.V. Kozhitov¹, S.G. Emelyanov, A.V. Vasilyev¹,2, A.V. Popkova ${ }^{4}$, A.A. Pavlova ${ }^{5}$ \\ 1 National University of Science and Technology MISiS, 4, Leninskiy prosp., 119049 Moscow, Russia \\ 2 A.V.Topchiev Institute of Petrochemical Synthesis, RAS, 29, Leninskiy prosp., 119991 Moscow, Russia \\ 3 Southwest State University, 94, 50 let Oktyabrya st., 305040 Kursk, Russia \\ 4 Tver State University, 33, Zhelyabova st., 170100 Tver, Russia \\ 5 National research Tomsk State University, 36, Lenin ave., 634050 Tomsk, Russia
}

(Received 11 May 2016; published online 03 October 2016)

\begin{abstract}
Nanoparticles of Fe-Co-Ni three-component alloy capsulated into carbon matrix were synthesized. Structure, phase composition and magnetic properties of obtained materials were defined by diffractometry and magnetometry. It was established that composition of nanoparticles is determine by synthesis temperature, because nanoparticles of three-component alloy are forms by dissolution of cobalt in $\mathrm{Fe}-\mathrm{Ni}$ alloy. Magnetization of $\mathrm{Fe}-\mathrm{Co}-\mathrm{Ni} / \mathrm{C}$ nanocomposites and coercive force increases from 26 up to $58 \mathrm{~A} \cdot \mathrm{m}^{2} / \mathrm{kg}$ during temperature increase that relates with growth of particles size and increase of cobalt content in the alloy.
\end{abstract}

Keywords: Synthesis, Metal-carbon composites, Nanoparticles of Fe-Co-Ni, Saturation magnetization, Coercive force, Squareness ratio.

DOI: $10.21272 /$ jnep.8(3).03037

PACS number: 82.50.Bc

\section{INTRODUCTION}

Considerable attention has been paid to the nanostructured materials, which is caused by specific magnetic properties which appear in nanosized state: high magnetization and coercitivity, high anisotropy, etc. Nanoparticles of alloy of Fe family are perspective at with view of their application in magnetic recording systems [1], high-frequency devices [2, 3], magnetic resonance tomography [4] and biomedicine [5], spintronics materials [6], shielding systems from microwaves in radioabsorbing materials [7-9].

Fe-Co-Ni alloys have high magnetically soft properties and high thermal stability [10]. Nanosized alloys of Fe-Co-Ni can be used in magnetic recording systems of high density [1] in different diminutive sensors and devices [11], as a catalyst [12].

Previously, possibility of synthesis of binary nanoparticles capsulated into a carbon matrix of metalcarbon nanocomposites synthesized based on polyacrylonitrile and salts of metals under infrared heating was shown [13, 14]. The aim of current investigation is synthesis of nanoparticles of $\mathrm{Fe}-\mathrm{Co}-\mathrm{Ni}$ three-component alloy capsulated into nanocomposite carbon matrix.

\section{EXPERIMENT}

Nonacomposites were synthesized according to the method described in [14]. However, salts of three metals were used. Precursors of composites were obtained from solvent of dimethylformamide (Fluka, 99.5\%) polyacrylonitrile, nitrate iron (III) crystalline hydrate (Acros Organics, $99 \%$ ), nitrates of cobalt (II) and nickel (II) hexahydrates (Acros Organics, $99 \%$ ) with further removal of solvent under temperature $T \leq 90{ }^{\circ} \mathrm{C}$ were obtained. Concentration of polyacrylonitrile in dimethylformamide solution was $5 \% \mathrm{wt}$. Total concentration of metals in precursor was $20 \% \mathrm{wt}$, ratio of metals was $\mathrm{Fe}: \mathrm{Co}: \mathrm{Ni}=1: 1: 1$ by mass.

$\mathrm{X}$-ray phase and X-ray diffraction analysys were carried out at the room temperature on X-ray diffractometer DIFRAY, Crka radiation. Magnetic properties were obtained by PPMS-14 by Quantum Design. Sensitivity of this method is $10^{-6} \mathrm{~A} \cdot \mathrm{m}^{2}$.

\section{RESULTS AND DISCUSSION}

During the infrared pyrolysis of polyacrylonitrile and formation of carbon matrix based on it there is an extraction of considerable amount of gas products including $\mathrm{H}_{2}, \mathrm{NH}_{3}$, CO which are reductants for metals compounds. It should be noted that the process of reduction takes place in solid phase of polymer. That is why the reduction of metal is in situ. In reduction atomic hydrogen formed by destruction of the main polymer chain under infrared heating is used.

Metal-carbon nanocomposites based on polyacrylonitrile and compounds of $\mathrm{Fe}$, Со и $\mathrm{Ni}$ were synthesized. $\mathrm{X}$-ray fluorescence analysis revealed that the formation of nanoparticles of three-component alloy occurs at 200$500{ }^{\circ} \mathrm{C}$. Phase analysis showed that for materials synthesized at $T \geq 500{ }^{\circ} \mathrm{C}$ significant lines of $\mathrm{FeNiCo}$ alloy $\left(2 \theta=67,8^{\circ}, 79^{\circ}, 132^{\circ}\right)$ are observed. Also there is slight content of hexagonal high density (HHD) phase of cobalt (Fig. 1)

There are a few phases of oxides (ferric oxide and nickel oxide) in obtained samples $\left(T=200^{\circ} \mathrm{C}\right)$, indicating that partial reduction of $\mathrm{Fe}_{2} \mathrm{O}_{3}$ to $\mathrm{FeO}$ with formation of $\mathrm{Fe}_{3} \mathrm{O}_{4}$ and, probably, nickel ferrite. Also, cobalt partially was reduced with formation of nanoparticles with HDD.

Increase in the temperature up to $500{ }^{\circ} \mathrm{C}$ leads to practically full reduction of metal oxides to metals with formation of Fe-Co-Ni alloy based on Ni-Fe solid solution and high temperature face-centered cubic lattice (FCL)

\footnotetext{
*muratov@ips.ac.ru
} 
of cobalt phase. There is low-temperature phase of cobalt HDD.

Further increase of temperature of nanocomposites synthesis induced higher intensity of lines of metal phase, indicating the growth of sizes pf alloy crystallite Fe-Co-Ni.

During the increase of synthesis temperature from 500 to $700{ }^{\circ} \mathrm{C} \mathrm{HDD}$ phase of cobalt disapears. Maximum of peak of the alloy goes to the left that indicates the growth of lattice constant. It is well known that cobalt and nickel generate a continuous row of solid solutions. The higher nickel concentration is the lower the lattice parameter solid solution is because nickel has smaller atomic radius.
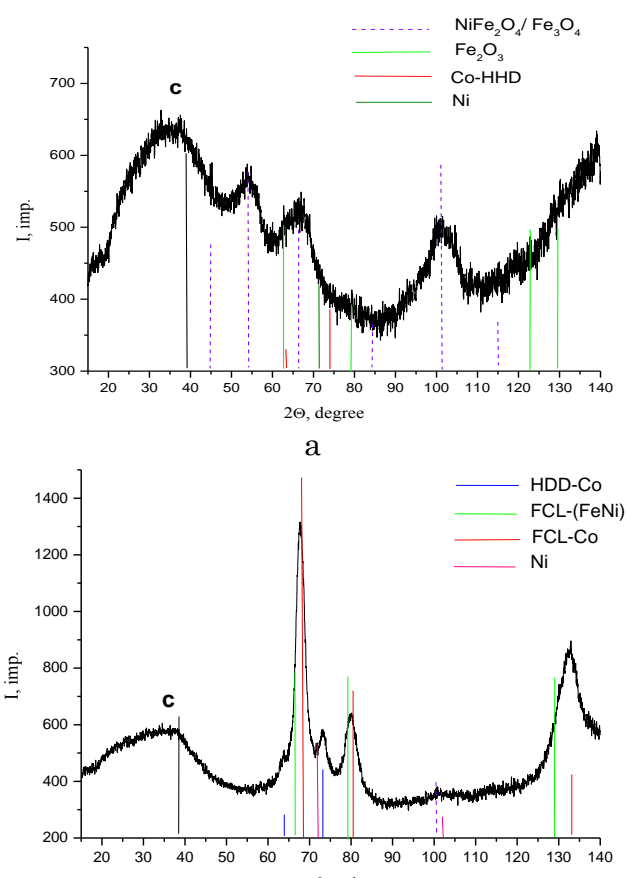

$\mathrm{b}$

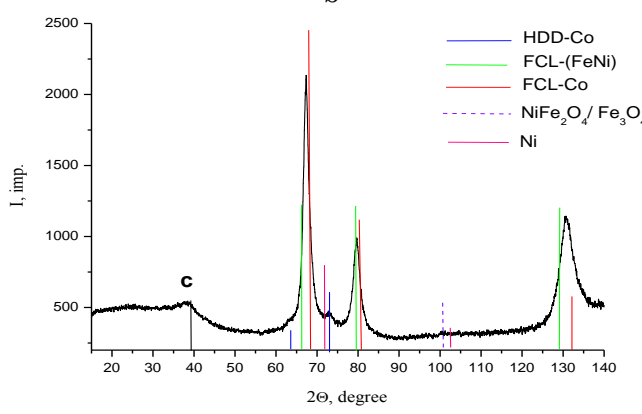

c

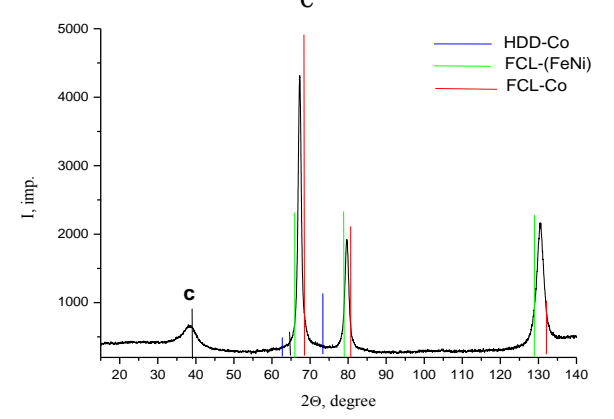

d

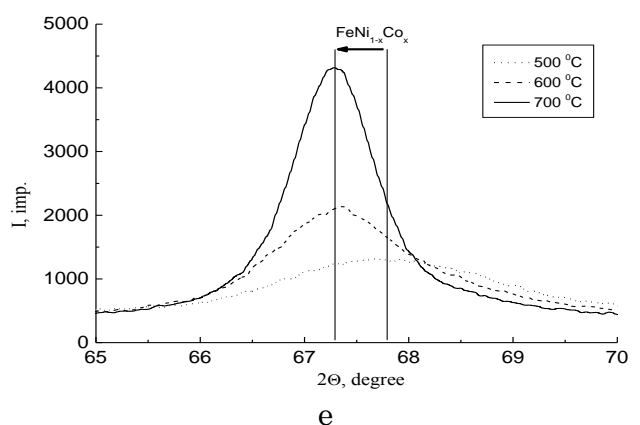

Fig. 1 - Diffraction pattern of nanocomposites synthesized at different temperatures: $200{ }^{\circ} \mathrm{C}$ (a), $500{ }^{\circ} \mathrm{C}$ (b), $600{ }^{\circ} \mathrm{C}$ (c), $700{ }^{\circ} \mathrm{C}$, fragment of dррагмент diffraction pattern $2 \theta=65-70^{\circ}$

There is the growth of lattice parameter in nanocomposites that indicates the dissolution of cobalt in FeNi alloy where cobalt replaces nickel. According to computation the average size of crystallite increases from $10-12$ to $23-25$ at the synthesis temperatures 500 $700{ }^{\circ} \mathrm{C}$.

At diffraction patterns of samples synthesized at $500{ }^{\circ} \mathrm{C}$ at the angles $20^{\circ}-40^{\circ}$ halo is obsereved, which is typical of the weakly ordered structures. Amorphous halo at X-ray pattern relates to the small size of coherent-scattering region of crystallite of graphite-alike phase. Also, halo is defined by bending and irregular displacement of grapheme planes from each other, as shown in [15]. The intensity of halo increases with increase of temperature that corresponds to a carbon matrix of nanocomposite, and its minimum shifts to angle of $39^{\circ}$ that corresponds to graphite planes $d_{002}$ that relates to processes of graphitization and formation of nanocrystall structure of matrix. Increase in lines intensity and shifting of maximum to area of big angles $2 \theta$ indicates the decrease of degree of matrix amorphism and increase in average size of crystallite of graphite-alike phase.

Analysis of magnetic properties of $\mathrm{FeNiCo} / \mathrm{C}$ nanocomposites confirms the results of X-ray phase and X-ray diffraction analysis (Fig. 2).

At the synthesis temperature ranged $200-500{ }^{\circ} \mathrm{C}$ there is considerable increase of magnetization of nanocomposites that relates with formation of metal alloy from appropriate oxides and with increase of nanoparticles size. In the synthesis temperature range of 500$700{ }^{\circ} \mathrm{C}$ there is increase of magnetization with increase of coercive force. The results are shown in Table 1.

Table 1 - Results of magnetic measurements of nanocomposites of $\mathrm{Fe}-\mathrm{Ni}-\mathrm{Co} / \mathrm{C}$

\begin{tabular}{|l|l|l|l|l|l|}
\hline $\begin{array}{l}\text { Synthesis } \\
\text { temperature, } \\
{ }^{\circ} \mathrm{C}\end{array}$ & $\begin{array}{l}M_{s}, \\
\mathrm{Am}^{2} / \mathrm{kg}\end{array}$ & $\begin{array}{l}M_{r}, \\
\mathrm{Am}^{2 /} \\
\mathrm{kg}\end{array}$ & $\begin{array}{l}H c, \\
\mathrm{Oe}\end{array}$ & $M_{r} / M_{s}$ & $d, \mathrm{~nm}$ \\
\hline 200 & 0,8 & 0,06 & 98 & 0,07 & $7-9$ \\
\hline 500 & 26 & 4,9 & 120 & 0,19 & $10-12$ \\
\hline 600 & 37 & 10 & 255 & 0,27 & $15-17$ \\
\hline 700 & 58 & 17,6 & 330 & 0,31 & $23-25$ \\
\hline
\end{tabular}




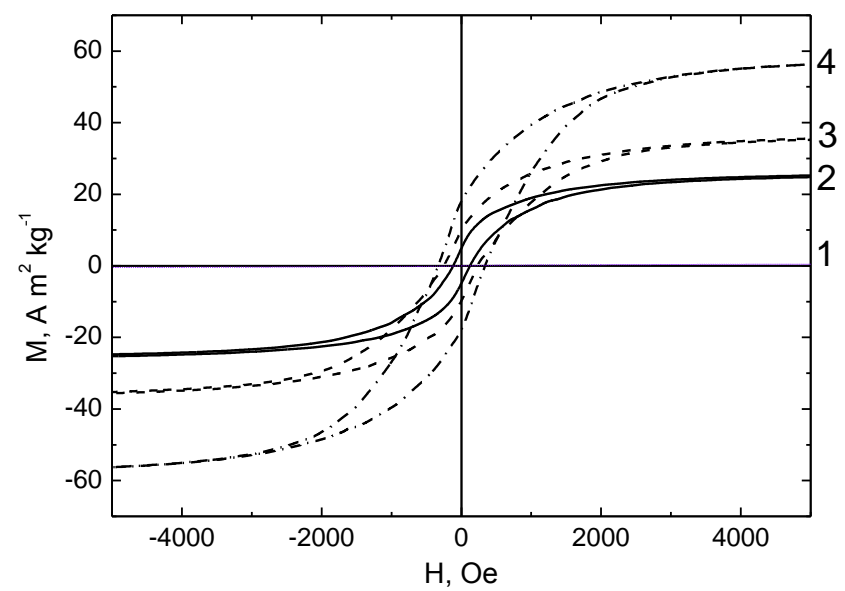

Fig. 2 - Loop of magnetization reversal of nanocomposites synthesized at different temperatures, ${ }^{\circ} \mathrm{C}: 200$ (1), 500 (2), 600 (3), 700 (4)

Analysis of values of magnetization and ratio shown that at synthesis temperature $T=200^{\circ} \mathrm{C}$ there is a primary formation of super paramagnetic nanoparticles that shows up in small value $M_{r} / M_{s}$ and saturation in fields greater than $10 \mathrm{kOe}$. Also low level of magnetization shows the absence of zero-valent metal or alloy. During the increase of synthesis temperature from 500 to $700{ }^{\circ} \mathrm{C}$ there is growth of saturation magnetization, residual magnetization and squareness ratio of hysteresis loop that indicates the nanoparticles size growth. Also during the increase of temperature the coercive force sufficiently increases from 120 to 330 Oe, which relates to dissolution of cobalt in $\mathrm{Fe}-\mathrm{Ni}$ alloy.

\section{REFERENCES}

1. D. Hisada, Y. Fujiwara, H. Sato, J. Magn. Magn. Mater. 323, 3184 (2011).

2. D. Hasegawa, H. Yang, T. Ogawa, M. Takahashi, J. Magn. Magn. Mater. 321, 746 (2009).

3. H.T. Yang, D. Hasegawa, M. Takahashi, T. Ogawa, Appl. Phys. Lett. 94, 013103 (2009).

4. J. Choi, J.H. Lee, T.H. Shin, J. Am. Chem. Soc. 132 (2010).

5. T. Kline, Y.-H. Xu, J. Magn. Magn. Mater. 321, 1525 (2009).

6. S.F. Marenkin, I.V. Fedorchenko, V.M. Trukhan, Russ. J. Inorg. Chem. 59, 355 (2014).

7. C. Ruxin, W.Y. Chunxia, B.Y. Ni, J. Environ. Sci. 23, S74 (2011).

8. P.H. Talemi, J. Azadmanjiri, G.P. Simon, Mater. Lett. 64, 1684 (2010).

9. X.G. Liu, Z.Q. Ou, D.Y. Geng, Z. Han, J.J. Jiang, W. Liu,

\section{CONCLUSION}

Thus, metal-carbon nanocomposites of $\mathrm{Fe}-\mathrm{Co}-\mathrm{Ni} / \mathrm{C}$ were synthesized using salt nitrate of metals and polyacrylonitrile under infrared heating. It was established that formation of homogeneous solid solution of these three metals was in condition of $33 \% \mathrm{wg}$. concentration of each metal in that case the FCL of alloy is forming. At temperature range of $200-500{ }^{\circ} \mathrm{C}$ the HDD phase of cobalt is observed. It should be mentioned that formation of alloy arises from metal oxides, which is formed by decomposition of nitrates and reduce under infrared heating.

Disagreement of lines maximums with diffraction pattern and etalon of FeNi and Co with FCL can be explained by formation of a three-component alloy. The process of alloy formation has a diffusive character that is expressed in shifting of lines maximums during the increase of synthesis temperature. It also influences growth of nanoparticles size. The average size of crystallite increase from $10-12$ to $23-25$ in synthesis temperature range of $500-700^{\circ} \mathrm{C}$.

Investigation of magnetic properties of nanocomposites confirms the results of X-ray diffraction analysis. Increase in magnetization and squareness ratio of hysteresis loop during the synthesis temperature increase indicates the nanoparticles size increase, whereas, increase of coercive force relates with dissolution of cobalt in naoparticles of $\mathrm{FeNi}$ alloy.

The research was carried out within the state assignment of Russian Ministry of Education and Science of National University of Science and Technology (theme №3035023 «Complex investigation of multifunctional materials 01.01.2014 - 31.12.2016) and President's grant for young scientists and graduate student № CП-3513.2016.1.

Z.D. Zhang, Carbon 48, 891 (2010).

10. A.A. El-Gendy, E.M.M. Ibrahim, V.O. Khavrus, Y. Krupskaya, S. Hampel, A. Leonhardt, B. Buchner, R. Klingeler, Carbon 47, 2821 (2009).

11. S. Mizutani, T. Yokoshima, H.S. Nam, T. Nakanishi, T. Osaka, Y. Yamazaki, IEEE T. Magn. 36 No 5, 2539 (2000).

12. A. Bai, C.C. Hu, T.C. Wen, Electrochim. Acta 48, 2425 (2003).

13. S. Vahid, A.A. Mirzaei, J. Ind. Eng. Chem. 20, 2166 (2014).

14. L.V. Kozhitov, D.G. Muratov, S.G. Emelyanov, J. NanoElectron. Phys. 6 No 3, 03040 (2014).

15. L.V. Kozhitov, D.G. Muratov, V.G. Kostishin, J. NanoElectr. Phys 6 No 3, 03038 (2014). 